\title{
Gonadal Development and Associated Changes in Estradiol, Thyroid Hormones, and Sex-Related Genes During Different Growth Stages in Cultured Female Rainbow Trout (Oncorhynchus Mykiss) in Yunnan
}

\section{Lingfu Kong}

Yunnan Agricultural University

\section{Baoliang Bi}

Yunnan Agricultural University

\section{Yanhua Su}

Yunnan Agricultural University

\section{Hua Rong}

Yunnan Agricultural University

Qing Hu ( $\nabla$ huqinggw@126.com )

Yunnan Agricultural University

\section{Research article}

Keywords: Oncorhynchus mykiss, gonadal development, serum hormones, gene transcription

Posted Date: November 13th, 2020

DOI: https://doi.org/10.21203/rs.3.rs-103765/v1

License: (c) (i) This work is licensed under a Creative Commons Attribution 4.0 International License. Read Full License 


\section{Abstract}

Background: Rainbow trout (Oncorhynchus mykiss) is an important fishing resource in Yunnan. However, the oocyte quality and fecundity are particularly affected by environmental factors when fish are undergoing sexual maturation, which hinders the development of the $O$. mykiss industry.

Results: Estradiol $\left(\mathrm{E}_{2}\right)$, thyroid hormones ( $\mathrm{THs}$ ), and sex-related genes transcription associated with gonadal development were analyzed in different growth stages of 0 . mykiss cultured in Yunnan. Females were classified into four growth stages: growth stage $\nabla$, growth stage $\nabla$, growth stage $\nabla$, and growth stage ه. Histological analysis found a correlated relationship between body growth and ovary development. Serum levels of $E_{2}$ and THs increased during ovarian development and reached the highest level at growth stage $\mathbb{Q}$ indicated that $E_{2}$ and THs play important roles in the development and maturation of oocytes in 0 . mykiss. Furthermore, real-time PCR analysis showed that the vitellogenin mRNA ( vtg) transcription level increased significantly both in ovaries and liver during ovarian development, then reaching its peak at the post-vitellogenetic (growth stage $\nabla$ ) period. The same transcription trend was detected in the levels of ovarian estrogen receptors (ers).

Conclusions: These results indicated that the high level of $\mathrm{E}_{2}$ promotes the transcription of the vtg mediated by different types of ers, and then accelerates the maturation of oocytes, and THs also participate in the regulation of maturation of oocytes in cultured 0 . mykiss during the individual development in Yunnan.

\section{Background}

Yunnan located in the Yunnan-Guizhou Plateau are topographically and climatically diverse. Yunnan is in a subtropical humid monsoon climate zone that includes tropical, subtropical, temperate and boreal climates [1]. Environmental conditions such as water temperature, water quality, lighting, and dietary nutrition, which in turn affect production traits including gonads development, reproduction, and growth in fish [2-4]. Rainbow trout (Oncorhynchus mykiss) is an important fishing resource in Yunnan, and it is also an expanding industry in several regions. Because of the oocyte quality and fecundity are particularly affected by environmental factors when fish are undergoing sexual maturation, it is important to attain knowledge about the oocyte development and how factors such as serum hormones and sexrelated genes involved in growth changed in cultured O. mykiss in Yunnan.

In teleost, it is well known that the hypothalamic-pituitary-gonadal (HPG) axis regulates the vitellogenesis and the final oocyte maturation during individual growing that mediate gonadotropic hormones (GtHs) actions via steroids secreted by the follicular cells surrounding the oocyte [5]. Correlation between changes in levels of sexual steroids (testosterone and 17ß-estradiol $\left(E_{2}\right)$ ) and oocyte development have been well documented in fish [6-8]. Moreover, studies showed that the hypothalamus-pituitary-thyroid (HPT) axis is also involved in gonad development [9]. For instance, thyroid hormones (THs) amplified the effects of $\mathrm{GtH}$ on $\mathrm{E}_{2}$ secretion by isolated ovarian follicles in rainbow trout (Salmo gairdneri) [10]. In 
Atlantic salmon (Salmo salar), THs were elevated before vitellogenesis and then decreased around the time when $E_{2}$ and vitellogenin (VTG) levels were known to rise [11]. However, in female brown trout (Salmo trutta), the discrepancies of plasma sex steroids observe between wild and cultured females may be due to differences in stress susceptibility, environmental conditions, life cycles, or to genetic divergence between the strains [12]. Therefore, changes in serum hormones during individual growth are important to be characterized and it will broaden the understanding of the relationship with the oocyte development and serum hormones in cultured O. mykiss in Yunnan.

VTG is a glycolipophosphoprotein produced in all oviparous species, which is biosynthesized in the liver under estrogen regulation and transported to the growing oocytes participating in the process of yolk formation $[13,14]$. In the liver of mature females teleost, $v t g$ transcription is stimulated via estrogen receptors (ers) signaling pathways due to the simultaneous increase of estrogen concentration [15]. Matured VTG produced in the liver was then transported to the ovary through the circulatory system. Thus, the amounts of $v t g$ transcription and translation have been widely used as biomarkers during oocyte development in certain teleost. In addition, ers play a crucial role in the mediation of estrogen activities. Four er isoforms (era1, era2, er $\beta 1$, and er $\beta 2$ ) have been detected and dominatingly expressed in the liver of 0 . mykiss [16]. These receptors may be important for estrogen signal conduction that initiates the next cycle of germ cell development in the ovary [17]. Therefore, understanding the function of ers in oocyte development during growing processes will be beneficial for improving the quality of cultured 0 . mykiss oocytes in the future.

Although the endocrine system of Oncorhynchus species has been relatively well studied, limited information is available about the relationship among oocyte development, serum hormones and sexrelated genes related to different growth stages. In the present study, we described the characteristics of oocyte development and analyzed the regulatory relationship among $\mathrm{E}_{2}, \mathrm{THs}$, and sex-related genes during different growth stages of $O$. mykiss. This study aims to clarify the regulation of oocyte development of 0 . mykiss cultured in plateau of Yunnan.

\section{Results}

\section{Histology}

Different growth stages of oocytes observed in the ovaries of 0 . mykiss were shown in Fig. 1. On growth stage $\nabla$ and growth stage $\varangle$, oocytes at primary yolk stage appeared and showed a higher percentage among other oocyte groups. On growth stage $₫$, ovaries were mostly occupied by filling yolk stage

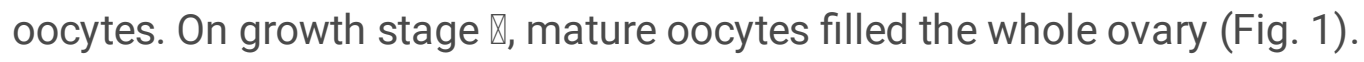

Figure 1 Histological sections of the ovaries of 0 . mykiss in different growth stages

(a) Oocyte at growth stage $\varangle$, (b) Oocyte at growth stage $\varangle$, (c) Oocyte at growth stage $\varangle$, (d) Oocyte at growth stage $\otimes, 0$ : Oocyte. The scale is $50 \mu \mathrm{m}$. 


\section{Serum hormones profile in female 0 . mykiss}

$\mathrm{E}_{2}$ levels in female 0 . mykiss ranged from $5.958 \mathrm{pg} / \mathrm{mL}$ to $1496.072 \mathrm{pg} / \mathrm{mL}$ in Fig. 2. $\mathrm{E}_{2}$ content was positively correlated with individual growth and oocyte development. There was no significant difference

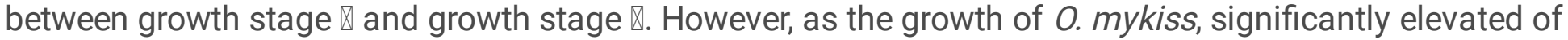
$\mathrm{E}_{2}$ level has been detected in growth stage $\otimes(p<0.05)$. Moreover, the highest value was recorded in growth stage $\otimes$ when the oocytes were matured $(p<0.05)$.

The levels of $\mathrm{THs}_{(}\left(\mathrm{T}_{4}, \mathrm{FT}_{4}, \mathrm{~T}_{3}, \mathrm{FT}_{3}\right)$ peaked in growth stage $\otimes(p<0.05)$ and were correlated with 0 . mykiss

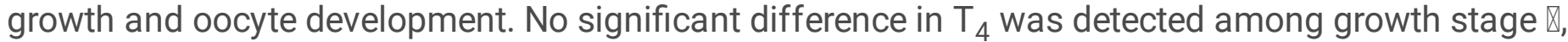

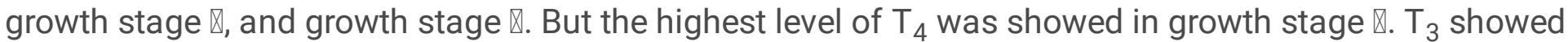

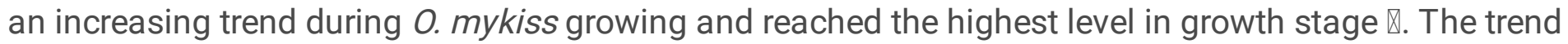
of $\mathrm{FT}_{4}$ during 0 . mykiss growing is similar to that of $\mathrm{T}_{4}$, while a higher level was also found in growth

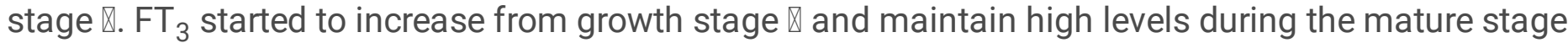
(Fig. 3).

Figure 2 Changes of serum $\mathrm{E}_{2}$ at different growth stages in 0 . mykiss

The $E_{2}$ levels in each growth stage is presented as mean $\pm S D(n=3)$. Different superscript letters indicate significant differences among different growth stages $(p<0.05)$.

Figure 3 Changes of serum THs at different growth stages in 0 . mykiss

(a) Changes of serum $\mathrm{T}_{4} ;$ (b) Changes of serum $\mathrm{T}_{3}$; (c) Changes of serum $\mathrm{FT}_{4}$; (d) Changes of serum $\mathrm{FT}_{3}$. The THs in each growth stage is presented as mean $\pm S D(n=3)$. Different superscript letters indicate significant differences among different growth stages $(p<0.05)$.

\section{Transcription profiles of sex-related genes during different growth stages in 0. mykiss}

Variations of the ers transcription during the different growth stages were analyzed in this study (Fig. 4a). The ers showed an irregular trend throughout the different growth stages, and on significant differences have been detected in the liver. In contrast, significant increases of era 1 and er $\beta 1$ transcription have been detected in the gonad and the highest level was shown in growth stage $\mathbb{Q}(p<0.05)$, while er $\beta 2$ did not fluctuate significantly during the different growth stages.

$v t g$ transcription was also continuously detected in all the analyzed individuals from 80.0 to $1200.0 \mathrm{~g}$.

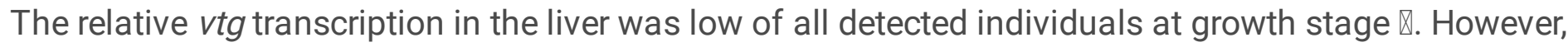
when the individuals continue to grow, $v t g$ transcription is gradually upregulated, and the highest level

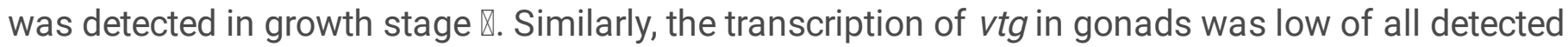
individuals at growth stage $\varangle$, growth stage $\varangle$, and growth stage $\otimes$. However, when the individuals growing

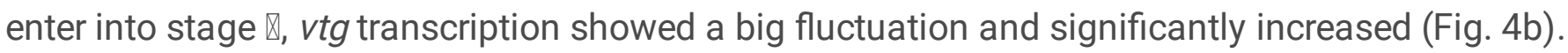


Figure 4 Relative transcriptions of sex-related genes of 0 . mykiss at different growth stages

(a) heatmap of ers mRNA transcription in liver and gonad, red represents a higher transcription and purple represent a lower transcription. (b) $v t g$ transcription level in liver and gonad. Values significantly difference are indicated by asterisks $\left({ }^{\star} p<0.05,{ }^{* \star} p<0.01\right)$.

\section{Discussion}

In this paper, we illustrated the relationship among the oocyte development, $E_{2}$, THs, and sex-related genes in 0 . mykiss during the different growth stages. The results showed that these indicators have an increasing trend among different growth stages associated with the oocyte development of cultured $O$. mykiss in Yunnan.

Investigating the developmental period of the oocytes during growing can reduce the time and cost to determine whether the cultured 0 . mykiss has reached sexual maturity. The result showed that oocytes at the primary yolk stage appeared and showed a higher percentage among other oocyte groups during 80$180 \mathrm{~g}$ of body weight. When the body weight above 700-1200 g, mature oocytes filled the whole ovary and can be ready for spawning. Study in sequential hermaphroditism species marbled swamp eel (Synbranchus marmoratus) showed that the females were sexually active with the mean total body length of $43.5 \mathrm{~cm}$ while the secondary males with about $58.5 \mathrm{~cm}$ [18]. Moreover, year 2-3 ovaries of $0.85-1.63 \mathrm{~kg}$ body weight were at stage I and year $4-5$ ovaries of $3.67-6.30 \mathrm{~kg}$ body weight were at stage II in different ages of Amur sturgeon (Acipenser schrenckii) [19]. Hence, there is a correlated relationship between body growth and ovary development. On the other hand, as a key hormone to promote the development of gonad in fish, the serum concentrations of $E_{2}$ significantly increased during the body growth of $O$. mykiss in this study, which corresponded with the development of ovarian histology. This result is consistent with the study of $S$. trutta in which the peak level of plasma $E_{2}$ were observed at $30 \mathrm{~d}$ before ovulation in the wild strain [12]. In cultured strain of $S$. trutta, the $E_{2}$ levels were the highest at the beginning and declined throughout two weeks before ovulation [12]. In female $S$. salar, $E_{2}$ were low from December to July and increased to peak levels in September and October during reproductively maturing period, and then decreased significantly during the period of ovulation in November [11]. In contrast, the levels of $E_{2}$ were not significantly different among different gonadal development stages in Sterlet (Acipenser ruthenus) [20]. These results indicated that $\mathrm{E}_{2}$ has different influences on different fish species and strains. Therefore, high level of $E_{2}$ contribute to the development and maturation of oocytes of cultured 0 . mykiss in this study.

THs also play important roles in the regulation of many biological processes in vertebrates, such as growth, metabolism, morphogenesis, and reproduction [21]. An early study demonstrated that THs can promote all stages of reproduction including the early stages gonadal (oocyte) development, vitellogenesis, and maturation leading to successful ovulation and spawning success [22]. Similarly, a recent study showed that the treatment to female goldfish (Carassius auratus) with $\mathrm{T}_{3}$ resulted in an 
increase of VTG [9]. In contrast, rabbitfish (Siganus guttatus) fed $\mathrm{T}_{4}$ during vitellogenesis did not advance oocyte maturation, but could induce spawning [23]. Moreover, in female $S$. trutta from a wild strain, the increase in plasma THs around the time of ovulation had an influence on final maturation of oocytes, while the absence of any appreciable change in profile of $\mathrm{T}_{4}$ indicated that the increase of THs are not necessary for ovarian maturation in cultured strain [12]. In our study, $T H s\left(T_{3}, T_{4}, F_{3}, F_{4}\right)$ all peaked

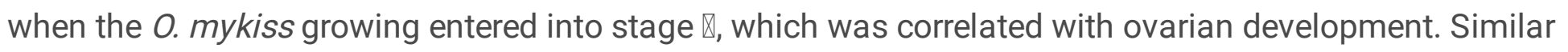
to $E_{2}$, elevated levels of THs contribute to the growing and final maturation of oocytes in cultured $O$. mykiss. Comparison of these results are complicated by several factors including different species and stock.

$E_{2}$ is synthesized by the cooperation of the theca and granulosa cell layers surrounding the oocytes, and secreted into the blood subsequently. VTG is produced by the liver in an estrogen-dependent manner by entering through diffusion, binding and activating the ERs [24]. Only three subtypes of ers (era1, erß1, and erß2) can be detected in our study. In teleost, ers expressed early during embryonic development and gonadal differentiation, suggesting the important role for estrogen in sexual differentiation in the early stage [25]. Estrogen receptor genes, such as era and er $\beta 2$, are involved in $\mathrm{E}_{2}$-induced liver vitellogenesis in medaka (Oryzias latipes), especially er $\beta 2$ [26]. In female zebrafish (Danio rerio), higher transcription levels of era and er $\beta 2$ were detected in the liver than er $\beta 1$ [27]. Similarly, as an important estrogen receptor gene subtype, era is also participated in the synthesis of liver vitellogenin induced by $E_{2}$ in several teleost fish [28]. Moreover, the up-regulation of era mediated by normal $E_{2}$ is regulated by $\operatorname{er} \beta 1$ and $\operatorname{er} \beta 2$ [29]. In this study, as the growth of 0 . mykiss, there was no significant correlation among the transcriptions of ers in the liver with the ovarian development. However, the transcription of $v t g$ in the liver gradually raised and reached its peak at growth stage $\nabla$ indicated that significantly increasing of $v t g$ transcription in the liver is stimulated by high levels of $E_{2}$ instead of ers in the later stage of vitellogenesis. Furthermore, the study of female Korean rockfish (Sebastes schlegeli) showed er $\beta 1$ and er $\beta 2$ highly expressed in the ovary at the vitellogenetic stage, which indicated that ers might play an important role in gonadal development [30]. In orange-spotted grouper (Epinephelus coioides), era highly expressed in mature ovaries, er $\beta 1$ mainly expressed in immature ovaries and er $\beta 2$ varied greatly during ovarian development. It speculated the potential roles of ers during female maturation [31]. The highest levels of era mRNA were found in late vitellogenetic ovaries of 0 . mykiss [32]. Similarly, in the present study, it was shown that ovarian ers (including era and er $\beta 1$ ) were sharply increased during 0 . mykiss growing and oocyte maturation. This result revealed an important role of ovarian ers in the maturation of $O$. mykiss oocyte cultured in Yunnan.

The vtg gene, which encodes VTG, is a precursor of lipo- and phospho-proteins involved in the formation of the yolk during oogenesis in the majority of vertebrates [33]. The previous study reported that $v t g$ is mainly expressed in the liver, but also various extrahepatic $v t g$ transcription was observed in fishes [34]. In female $A$. ruthenus, vtg transcription has been detected both in the liver and ovary, and they both reached its peak at the late vitellogenetic stage [35]. During the 0 . mykiss growing and ovary development, $v t g$ transcription in this study exhibited an increasing trend both in the liver and ovaries, and reached its peak at the late growth and vitellogenetic stage (growth stage $\varangle$ ). In general, the rise in vtg 
level in both liver and ovaries during vitellogenesis period, which correspond with the VTG and eggshell proteins incorporation into the oocyte, and the accumulation of enough nutrients for developing embryos [36]. We also propose that the liver and ovaries are both the sites of VTG synthesis in 0 . mykiss. Moreover, the transcription of $v t g$ was in parallel with the level of serum $\mathrm{E}_{2}$, indicated that $\mathrm{E}_{2}$ plays an important role in inducing the transcription of $v t g$. Summarizing the results of ers transcription, it demonstrated that the high level of $\mathrm{E}_{2}$ promotes the transcription of the $v t g$ mediated by different types of ers, and then accelerates the maturation of oocytes in cultured 0 . mykiss.

\section{Conclusions}

In conclusion, it was found that oocyte development, $\mathrm{E}_{2}$, THs, and sex-related genes all significantly increased during the growth of $O$. mykiss. The serum concentrations of $\mathrm{E}_{2}$ corresponded with the development of ovary during $O$. mykiss growing indicated that $\mathrm{E}_{2}$ plays an important role in the development and maturation of oocytes. Similarly, $\mathrm{THs}\left(\mathrm{T}_{3}, \mathrm{~T}_{4}, \mathrm{FT}_{3}, \mathrm{FT}_{4}\right)$ peaked at the highest level in growth stage $\otimes$ reflected that THs contribute to the $O$. mykiss growing and final maturation of oocytes. Increasing levels of ers and $v t g$ transcription during 0 . mykiss growing demonstrated an important role of ers in the maturation of oocytes. Therefore, the high level of $\mathrm{E}_{2}$ promotes the transcription of the $v t g$ mediated by different types of ers, and then accelerates the maturation of oocytes in cultured 0 . mykiss.

\section{Methods}

\section{Fish sampling}

The cultured 0 . mykiss was obtained from Tanghao Aquaculture Company located in Kunming, China. Sampling permissions were also obtained for the Tanghao Aquaculture Company. Sampling was carried out in July when fish were in the peak of growth and development. The bodyweight of 0 . mykiss ranged from $80.0 \mathrm{~g}$ to $1200.0 \mathrm{~g}(\mathrm{n}=12)$. They were divided into four different growth stages, which are growth stage $\otimes(80-120 \mathrm{~g})$, growth stage $\otimes(160-180 \mathrm{~g})$, growth stage $\otimes(280-400 \mathrm{~g})$, growth stage $\otimes(700-$ $1200 \mathrm{~g}$ ), respectively. Fish were fasted for $24 \mathrm{~h}$ and then anesthetized by $100 \mathrm{mg} / \mathrm{L}$ tricaine methanesulfonate (MS-222, Sigma, St. Louis, MO) till the cessation of opercular movements for about 5 min before sampling. Blood samples were withdrawn from the fish caudal vein with a syringe and centrifuged at $1,500 \mathrm{~g}$ for $30 \mathrm{~min}$. The serum of fishes in each growth stage was pooled and then quickly frozen at $-80^{\circ} \mathrm{C}$ for sequential detect of $\mathrm{E}_{2}$, and $\mathrm{THs}\left(\mathrm{T}_{3}, \mathrm{~T}_{4}, \mathrm{FT}_{3}, \mathrm{FT}_{4}\right)$. Then, the ovaries were rapidly excised and fixed in Bouin's fluid for determined the histological characteristics. Furthermore, the ovaries and liver of each fish were frozen at $-80^{\circ} \mathrm{C}$ for the determination of gene transcription. The usage of fish was in strict accordance with the recommendations of the Guidelines for the Use of Experimental Animals of Yunnan Agricultural University. The protocol for animal care and handling used in this study was approved by the Committee on the Ethics of Animal Experiments of Yunnan Agricultural University.

\section{Histology}


For histological studies, ovaries of each growth stage were embedded in paraffin and sectioned at 5$6 \mu \mathrm{m}$. Sections were stained with hematoxylin and eosin. After staining, the slides were allowed to dry and then examined with a light microscope (Olympus BX51, Japan).

\section{$E_{2}$ analyses}

The levels of $E_{2}$ were measured by using commercially available ${ }^{125}$ I-RIAs assay (Beijing North Institute of Biotechnology Co., Ltd., Beijing, China) in serum according to the manufacturer's instruction. The kit uses competitive radioimmunoassay to simultaneously compete for binding of radiolabeled antigens and non-labeled antigens to a limited amount of specific antibodies. The radioactive count of the labeled antigen-antibody complex is determined by separating the unbound labeled antigen. The content of $E_{2}$ in the samples was calculated using the standard curve and the mathematical model of the RIAs. All samples were analyzed in five duplicates. The RIAs for $\mathrm{E}_{2}$ in the 0 . mykiss serum samples were validated by demonstrating parallelism between a series of diluted and spiked samples to the standard curve.

\section{Thyroid hormones analyses}

THs in serum were measured using commercial ELISA kits purchased from Beijing North Institute of Biotechnology Co., Ltd., Beijing, China, following the manufacturer's instructions. All samples were analyzed in three duplicates and a separate standard curve was run for each ELISA plate. The assay sensitivities were $10 \mathrm{ng} / \mathrm{mL}, 0.25 \mathrm{ng} / \mathrm{mL}, 1.08 \mathrm{pmol} / \mathrm{L}$, and $0.38 \mathrm{pmol} / \mathrm{L}$, for $\mathrm{T}_{4}, \mathrm{~T}_{3}, \mathrm{FT}_{4}$, and $\mathrm{FT}_{3}$, respectively.

\section{RNA extraction and reverse transcription-PCR}

Total RNA in ovaries and liver of each fish was extracted using TRIpure reagent (Aidlab Biotechnologies Co., Ltd., Beijing, China) according to the manufacturer's instructions. The concentration of RNA was measured using NanoDrop 2000c (Thermo Scientific, USA). Total RNA with the amount of $1 \mu \mathrm{g}$ of each sample was used for reverse transcription with TRUEscript 1st Strand cDNA Synthesis Kit with gDNA Eraser (Aidlab Biotechnologies Co., Ltd., Beijing, China) in a final reaction volume of $20 \mu \mathrm{L}$.

\section{Transcription of sex-related genes}

Relative quantitative real-time PCR was used to detect the transcription of sex-related genes. The primers for genes used in this study were shown in Table 1. Elongation factor $1 a($ ef1a) was used as the reference gene. The specificity of each pair of primers was verified via the only peak of the melting curve. PCR reactions $(20 \mu \mathrm{L})$ contained $1 \mu \mathrm{L}$ of cDNA diluted five times, $0.5 \mu \mathrm{L}$ of $10 \mathrm{mM}$ of each primer, and $10 \mu \mathrm{L}$ of $2 \times$ SYBR qPCR Mix (Aidlab Biotechnologies Co., Ltd., Beijing, China). Amplification of these genes was: pre-heating at $95^{\circ} \mathrm{C}$ for $3 \mathrm{~min}$, followed by 40 cycles of $95^{\circ} \mathrm{C}$ for $30 \mathrm{~s}, 53^{\circ} \mathrm{C}$ for $30 \mathrm{~s}$, and a final extension step at $72{ }^{\circ} \mathrm{C}$ for $30 \mathrm{~s}$. The samples were analyzed in triplicate in a Light Cycler 480II/96 (Roche Diagnostics International Ltd, Switzerland). Negative control was included in each assay without cDNA. The mRNA transcription level of each gene was calculated by the $2^{-\Delta \Delta \mathrm{Ct}}$ method [37]. 
Table 1

Nucleotide primers used in Real-time PCR

\begin{tabular}{|c|c|c|c|}
\hline Gene & Primer name & Sequence $\left(5^{\prime}-3^{\prime}\right)$ & GenBank No. or Article source \\
\hline \multirow[t]{2}{*}{$v t g$} & $v \operatorname{tg}-\mathrm{F}$ & GTGGACTGGATGAAGGGACA & \multirow[t]{2}{*}{ AY049952.1 } \\
\hline & $v \operatorname{tg}-\mathrm{R}$ & AGAGCGGCTCAGGTTGGAAT & \\
\hline \multirow[t]{2}{*}{ era 1} & era1-F & СCCTGCTGGTGACAGAGAGAA & \multirow[t]{2}{*}{ [16] } \\
\hline & era1-R & АTCCTCCACCACCATTGAGACT & \\
\hline \multirow[t]{2}{*}{ er $\beta 1$} & erß1-F & CCCAAGCGGGTCCTAGCT & \multirow[t]{2}{*}{ [16] } \\
\hline & erß1-R & TCСTCATGTCCTTCTGGAGGAA & \\
\hline \multirow[t]{2}{*}{ erß2 } & erß2-F & CTGACCCCAGAACAGCTGATC & \multirow[t]{2}{*}{ [16] } \\
\hline & erß2-R & TCGGCCAGGTTGGTAAGTG & \\
\hline \multirow[t]{2}{*}{ ef1a } & ef7a-F & AGGCCATCTGATCTACAAGTGC & \multirow[t]{2}{*}{ AF498320.1 } \\
\hline & ef7a-R & GGTGATACCACGCTCCCTCT & \\
\hline
\end{tabular}

[Table 1]

\section{Statistical analysis}

Data analysis was performed using SPSS 16.0 software (IBM, USA). The differences among each stage were evaluated by one-way analysis of variance (ANOVA) followed by the Least Significant Difference (LSD) post-hoc test. All the data were expressed as mean \pm standard deviation (SD).

\section{Abbreviations}

$\mathrm{E}_{2}$ : estradiol; ef1a: elongation factor $1 a$, ers: estrogen receptors; GtHs: gonadotropic hormones; THs: thyroid hormones ( $\mathrm{T}_{3}$ : triiodothyronine; $\mathrm{T}_{4}$ : thyroxine; $\mathrm{FT}_{3}$ : free triiodothyronine; $\mathrm{FT}_{4}$ : free thyroxine); $\mathrm{VTG}$ : vitellogenin; $v t g$. vitellogenin mRNA

\section{Declarations}

\section{Ethics approval and consent to participate}

The usage of fish was in strict accordance with the recommendations of the Guidelines for the Use of Experimental Animals of Yunnan Agricultural University. The protocol for animal care and handling used in this study was approved by the Committee on the Ethics of Animal Experiments of Yunnan Agricultural University. 
Not applicable.

\section{Availability of data and materials}

Not applicable. All data generated or analyzed during this study are included in this article.

\section{Competing interests}

The authors declare that they have no conflict of interest.

\section{Funding}

This work was supported by the National Natural Science Foundation of China (grant number 31602141) and the Yunnan Fundamental Research Projects (grant number 2017FD077). The funding agencies mainly provided financial support for the purchase of experimental fish and reagents during the experiment. But they had no role in the design of the study and collection, analysis, and interpretation of data and in writing the manuscript.

\section{Authors' contributions}

QH designed the experiments and analyzed the experimental results. LFK and BLB carried out the experiments and wrote the manuscript. YHS, HR and QH helped to finish the experiments and the manuscript. All authors read and approved the final manuscript.

\section{Acknowledgements}

We are grateful to Prof. Dapeng Li at the College of Fisheries in Huazhong Agricultural University in Wuhan Laboratory for analyzing the plasma biochemistry parameters and genes transcription. We are further grateful to Tanghao Aquaculture Company in Kunming of China for donating juvenile O. mykiss and for their support and advice of 0 . mykiss aquaculture. We are also grateful to Prof. Junming Deng for the Fish breeding base and the Laboratory of tissue history analyze. We are appreciative of the help provided by the undergraduate students of Plateau Aquacultural College of Yunnan Agricultural University for fish breeding, histological processing and morphometric analyses in O. mykiss.

\section{Authors' Information}

\section{Lingfu Kong}

E-mail Address: 309011288@qq.com

Institution: Yunnan Agricultural University

2. Baoliang Bi

E-mail Address: 1448151770@qq.com 
Institution: Yunnan Agricultural University

3. Yanhua Su

E-mail Address: 522852288@qq.com

Institution: Yunnan Agricultural University

4. Hua Rong

E-mail Address: 418516991@qq.com

Institution: Yunnan Agricultural University

5. Qing $\mathrm{Hu}$

E-mail Address: huqinggw@126.com

Institution: Yunnan Agricultural University

\section{References}

1. Liu X, Li Y. Aquaculture enclosures relate to the establishment of feral populations of introduced species. PLoS ONE. 2009; 4(7):e6199.

2. Masoudi Asil S, Abedian Kenari A, Rahimi Miyanji G, Van Der Kraak G. The influence of dietary arachidonic acid on growth, reproductive performance, and fatty acid composition of ovary, egg and larvae in an anabantid model fish, Blue gourami (Trichopodus trichopterus; Pallas, 1770). Aquaculture. 2017; 476:8-18.

3. Weber GM, Davidson JW, Kenney PB, Good CM, Manor ML, Welsh C, Aussanasuwannakul A, Summerfelt ST. Changes in sex steroids, growth hormone, and insulin-like growth factor- $₫$ during ovarian development in rainbow trout cultured in a water recirculating system with continuous light. N Am J Aquac. 2015; 77(2):186-194.

4. Sloat MR, Reeves GH, Jonsson B. Individual condition, standard metabolic rate, and rearing temperature influence steelhead and rainbow trout (Oncorhynchus mykiss) life histories. Can J Fish Aquat Sci. 2014; 71(4):491-501.

5. Nagahama Y, Yoshikuni M, Yamashita M, Tanaka M. 13 Regulation of oocyte maturation in fish. In: Molecular Endocrinology of Fish. vol. 13: Academic Press; 1994: 393-439.

6. Dahle R, Taranger GL, Karlsen O, Kjesbu OS, Norberg B. Gonadal development and associated changes in liver size and sexual steroids during the reproductive cycle of captive male and female Atlantic cod (Gadus morhua L.). Comp Biochem Physiol A Mol Integr Physiol. 2003; 136(3):641-653.

7. Kumar P, Arasu A, Kailasam M, Sukumarran K, Subburj R, Tyagraj G, Natarajan M. Gonadal development and steroid hormone profile of wild caught grey mullet (Mugil cephalus). Biol Rhythm 
Res. 2015; 46(4):601-610.

8. Farrokhnejad MR, Amiri BM, Abdoli A, Nazari H. Gonadal histology and plasma sex steroid concentrations in maturing and mature spring migrants of Caspian lamprey Caspiomyzon wagneri in the Shirud River, southern Caspian Sea, Iran. Ichthyol Res. 2014; 61(1):42-48.

9. Nelson ER, Habibi HR. Thyroid hormone regulates vitellogenin by inducing estrogen receptor alpha in the goldfish liver. Mol Cell Endocrinol. 2016; 436:259-267.

10. Cyr DG, Eales J. In vitro effects of thyroid hormones on gonadotropin-induced estradiol-17 secretion by ovarian follicles of rainbow trout, Salmo gairdneri. Gen Comp Endocrinol. 1988; 69(1):80-87.

11. Dickhoff WW, Yan L, Plisetskaya EM, Sullivan CV, Swanson P, Hara A, Bernard MG. Relationship between metabolic and reproductive hormones in salmonid fish. Fish Physiol Biochem. 1989; 7(1):147-155.

12. Norberg B, Björnsson BT, Brown CL, Wichardt U-P, Deftos LJ, Haux C. Changes in plasma vitellogenin, sex steroids, calcitonin, and thyroid hormones related to sexual maturation in female brown trout (Salmo trutta). Gen Comp Endocrinol. 1989; 75(2):316-326.

13. Reading B, Sullivan C, Schilling J. Vitellogenesis in fishes. Reference Module in Life Sciences. 2017.

14. Nagahama Y, Yoshikuni M, Yamashita M, Tokumoto T, Katsu Y. 4 Regulation of oocyte growth and maturation in fish. In: Curr Top Dev Biol. vol. 30: Elsevier; 1995: 103-145.

15. Shanthanagouda AH, Nugegoda D, Hassell KL, Patil JG. Exposure to estrogenic chemicals induces ectopic expression of $v t g$ in the testis of rainbowfish, Melanotaenia fluviatilis. Bull Environ Contam Toxicol. 2013; 91(4):438-443.

16. Nagler JJ, Cavileer T, Sullivan J, Cyr DG, Rexroad III C. The complete nuclear estrogen receptor family in the rainbow trout: discovery of the novel ERa2 and both $E R \beta$ isoforms. Gene. 2007; 392(1):164173.

17. Nagler JJ, Cavileer TD, Verducci JS, Schultz IR, Hook SE, Hayton WL. Estrogen receptor mRNA expression patterns in the liver and ovary of female rainbow trout over a complete reproductive cycle. Gen Comp Endocrinol. 2012; 178(3):556-561.

18. Barros NHC, de Souza AA, Chellappa S. Histological aspects of gonad development in the Diandric Protogynous Sequential Hermaphrodite fish Synbranchus marmoratus (Osteichthyes: Synbranchidae). Anim Biol J. 2012; 3(4):159.

19. Qu QZ, Sun DJ, Wan BQ, Ma GJ. The relationships between gonad development and sex steroid levels at different ages in Acipenser schrenckii. J Appl Ichthyol. 2010; 26(1):1-5.

20. Wang W, Zhu H, Dong Y, Tian Z, Dong T, Hu H, Niu C. Dimorphic expression of sex-related genes in different gonadal development stages of sterlet, Acipenser ruthenus, a primitive fish species. Fish Physiol Biochem. 2017; 43(6):1557-1569.

21. Blanton ML, Specker JL. The hypothalamic-pituitary-thyroid (HPT) axis in fish and its role in fish development and reproduction. Crit Rev Toxicol. 2007; 37(1-2):97-115. 
22. Cyr DG, Eales J. Interrelationships between thyroidal and reproductive endocrine systems in fish. Rev Fish Biol Fish. 1996; 6(2):165-200.

23. Pham HQ, Le HM. Effects of thyroxin and domperidone on oocyte maturation and spawning performances in the rabbit fish, Siganus guttatus. J World Aquacult Soc. 2016; 47(5):691-700.

24. Leatherland J, Li M, Barkataki S. Stressors, glucocorticoids and ovarian function in teleosts. J Fish Biol. 2010; 76(1):86-111.

25. Lassiter CS, Kelley B, Linney E. Genomic structure and embryonic expression of estrogen receptor beta a (ERßa) in zebrafish (Danio rerio). Gene. 2002; 299(1-2):141-151.

26. Tapas C, Yasushi S, Lin-Yan Z, Yoshinao K, Taisen I, Yoshitaka N. Differential expression of three estrogen receptor subtype mRNAs in gonads and liver from embryos to adults of the medaka, Oryzias latipes. Mol Cell Endocrinol. 2011; 333(1):47-54.

27. Meng X, Bartholomew C, Craft JA. Differential expression of vitellogenin and oestrogen receptor genes in the liver of zebrafish, Danio rerio. Anal Bioanal Chem. 2010; 396(2):625-630.

28. Sabo-Attwood T, Kroll KJ, Denslow ND. Differential expression of largemouth bass (Micropterus salmoides) estrogen receptor isotypes alpha, beta, and gamma by estradiol. Mol Cell Endocrinol. 2004; 218(1-2):107-118.

29. Nelson ER, Habibi HR. Functional significance of nuclear estrogen receptor subtypes in the liver of goldfish. Endocrinology. 2010; 151(4):1668-1676.

30. Mu W, Wen H, Shi D, Yang Y. Molecular cloning and expression analysis of estrogen receptor betas (ERß1 and ERß2) during gonad development in the Korean rockfish, Sebastes schlegeli. Gene. 2013; 523(1):39-49.

31. Chen H, Zhang Y, Li S, Lin M, Shi Y, Sang Q, Liu M, Zhang H, Lu D, Meng Z et al. Molecular cloning, characterization and expression profiles of three estrogen receptors in protogynous hermaphroditic orange-spotted grouper (Epinephelus coioides). Gen Comp Endocrinol. 2011; 172(3):371-381.

32. Nagler J, Krisfalusi M, Cyr D. Quantification of rainbow trout (Oncorhynchus mykiss) estrogen receptor-alpha messenger RNA and its expression in the ovary during the reproductive cycle. J Mol Endocrinol. 2000; 25(2):243-251.

33. Finn RN. Vertebrate yolk complexes and the functional implications of phosvitins and other subdomains in vitellogenins. Biol Reprod. 2007; 76(6):926-935.

34. Zhong L, Yuan L, Rao Y, Li Z, Zhang X, Liao T, Xu Y, Dai H. Distribution of vitellogenin in zebrafish (Danio rerio) tissues for biomarker analysis. Aquat Toxicol. 2014; 149:1-7.

35. Akhavan SR, Salati AP, Falahatkar B, Jalali SAH. Erratum to: Changes of vitellogenin and Lipase in captive Sterlet sturgeon Acipenser ruthenus females during previtellogenesis to early atresia. Fish Physiol Biochem. 2016; 42(5):1491-1491.

36. Lubzens E, Young G, Bobe J, Cerdà J. Oogenesis in teleosts: how fish eggs are formed. Gen Comp Endocrinol. 2010; 165(3):367-389. 
37. Livak KJ, Schmittgen TD. Analysis of relative gene expression data using real-time quantitative PCR and the $2-\Delta \Delta C T$ method. Methods. 2001; 25(4):402-408.

\section{Figures}
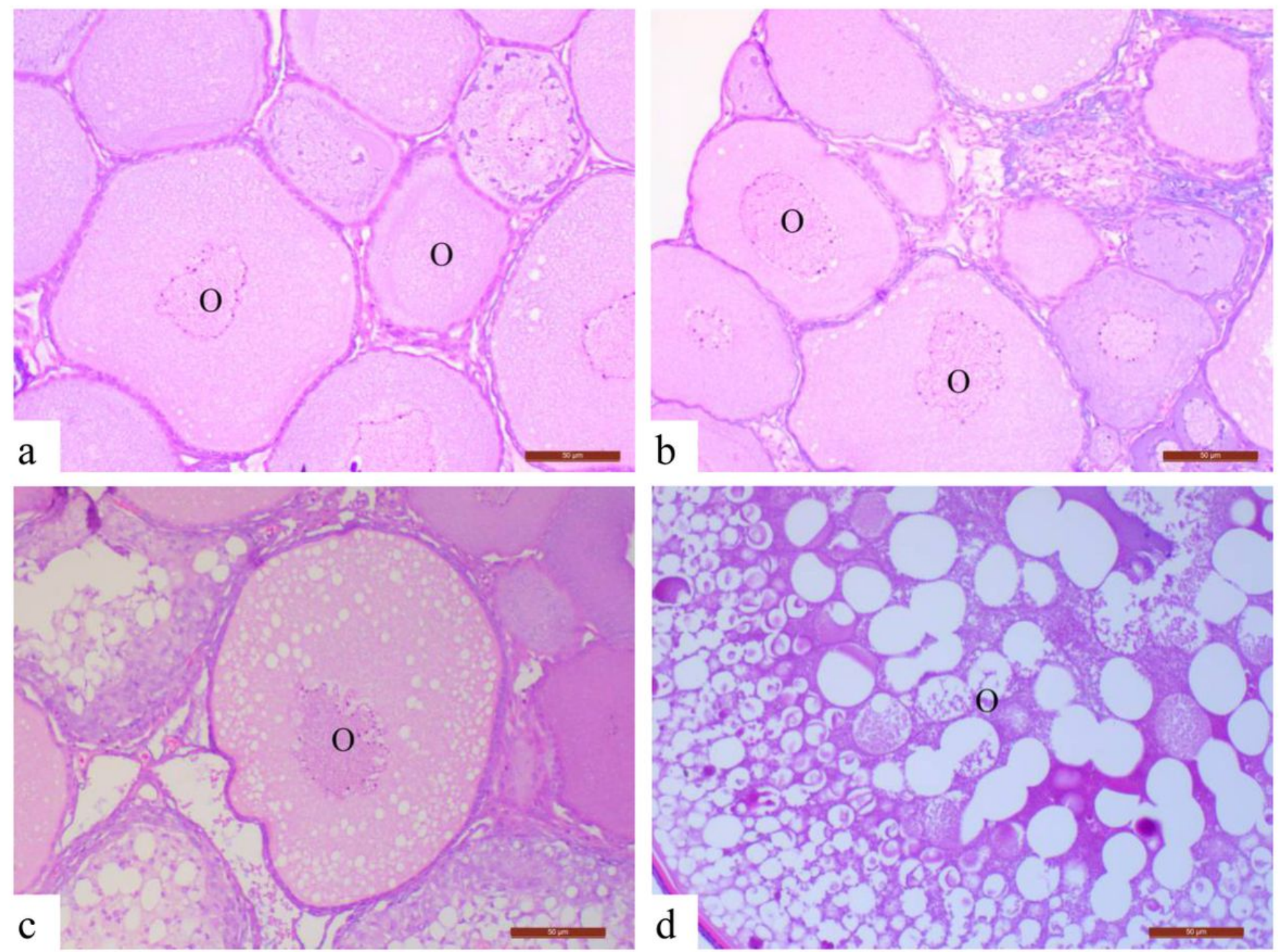

\section{Figure 1}

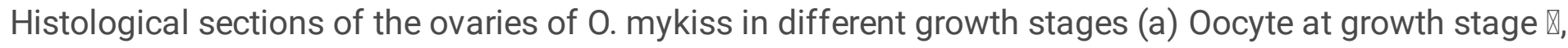
(b) Oocyte at growth stage $\varangle$, (c) Oocyte at growth stage $\varangle$, (d) Oocyte at growth stage $\varangle, 0$ : Oocyte. The scale is $50 \mu \mathrm{m}$. 

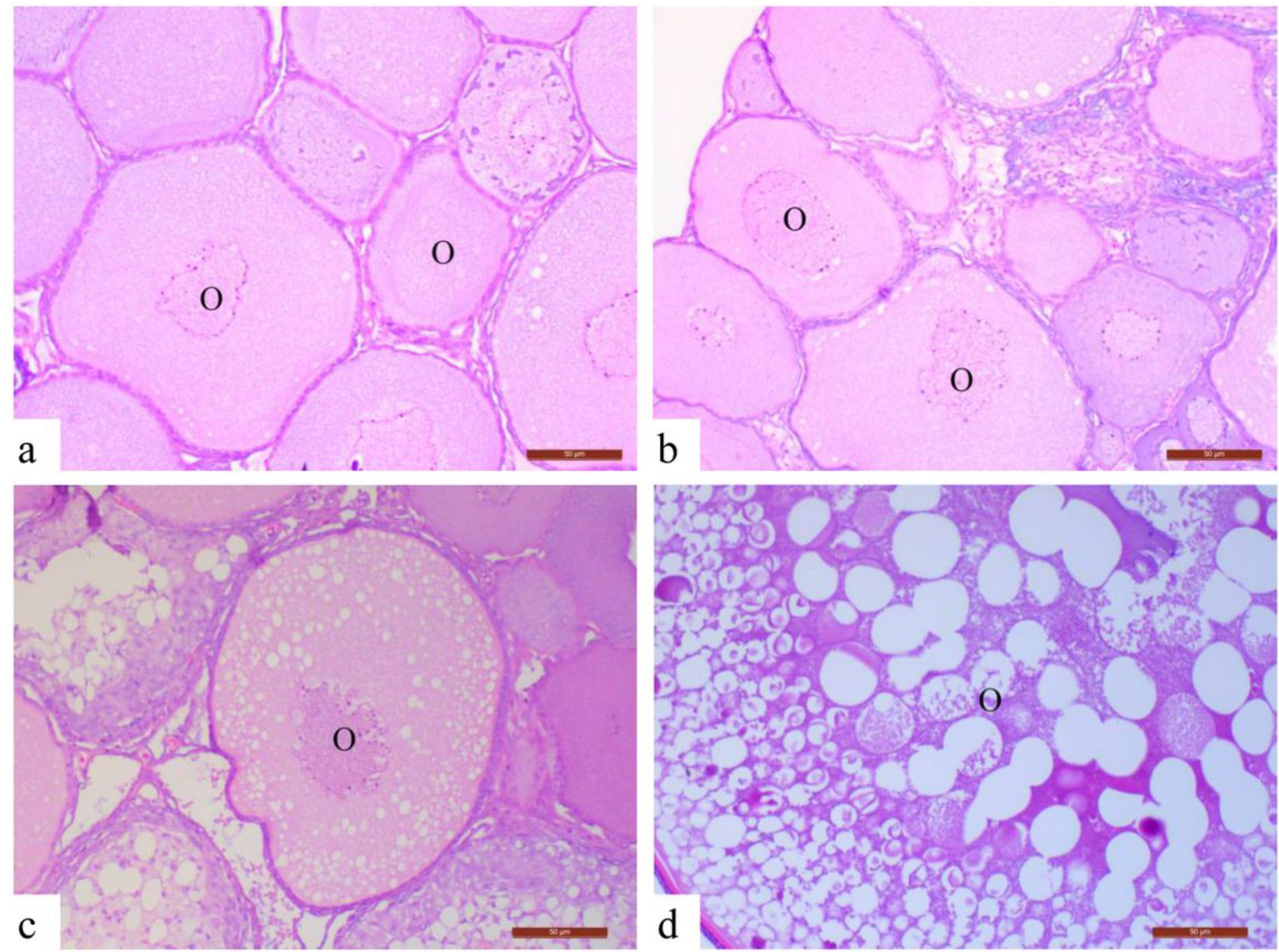

\section{Figure 1}

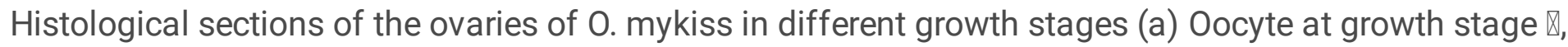

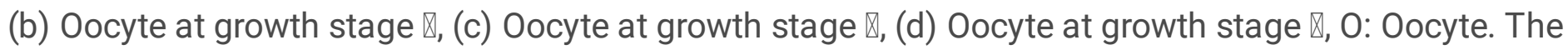
scale is $50 \mu \mathrm{m}$. 


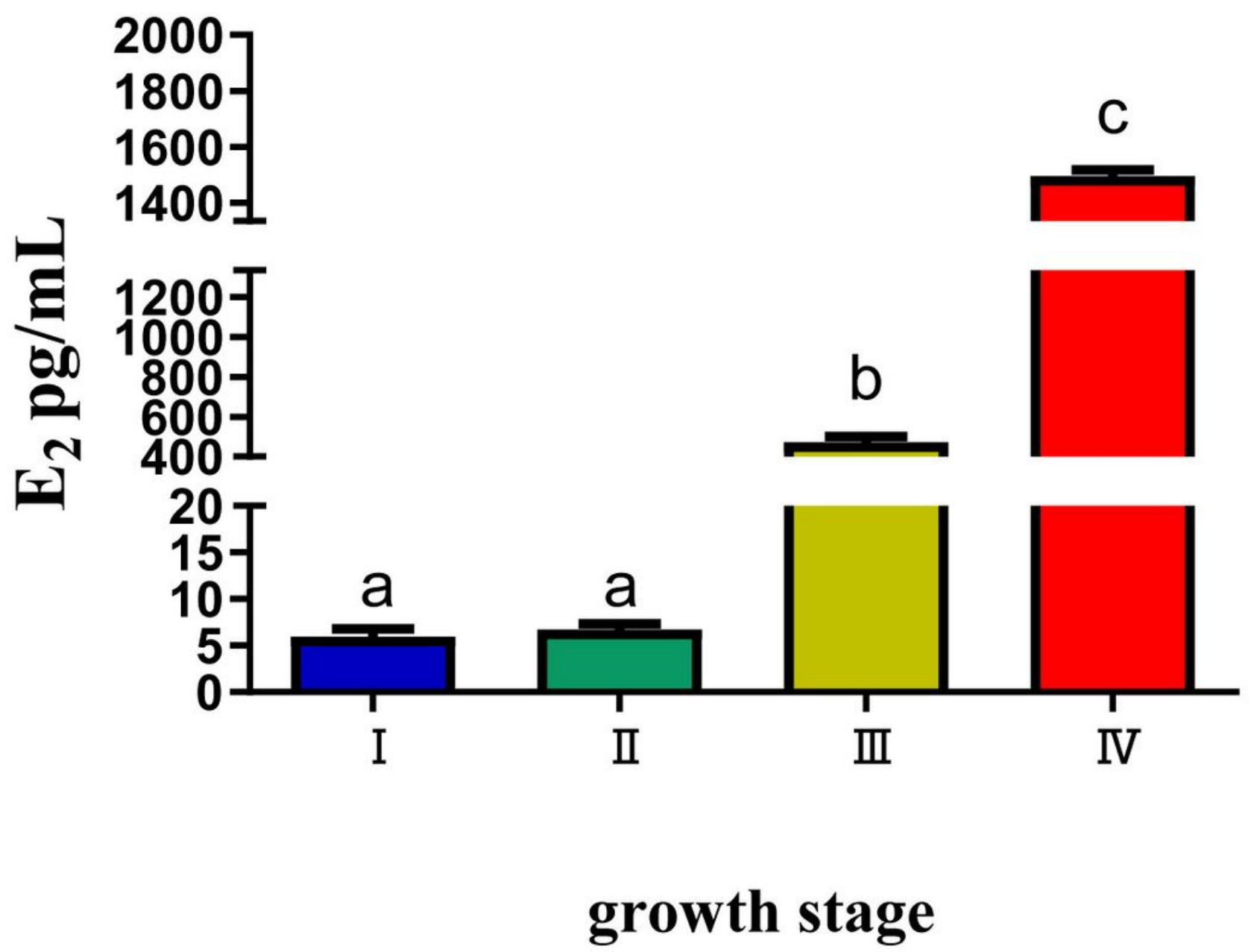

Figure 2

Changes of serum E2 at different growth stages in 0. mykiss The E2 levels in each growth stage is presented as mean $\pm S D(n=3)$. Different superscript letters indicate significant differences among different growth stages $(p<0.05)$. 


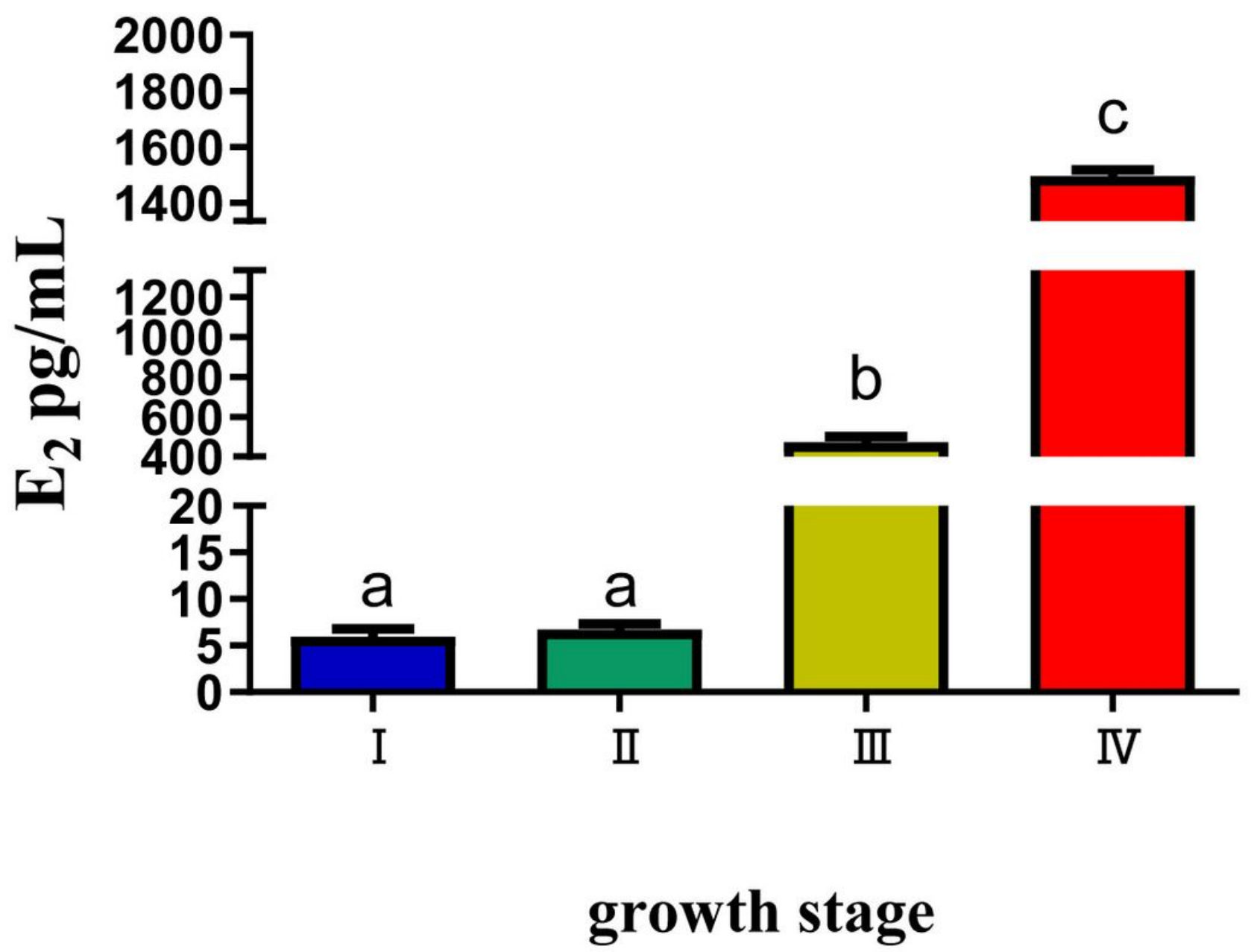

Figure 2

Changes of serum E2 at different growth stages in 0. mykiss The E2 levels in each growth stage is presented as mean $\pm S D(n=3)$. Different superscript letters indicate significant differences among different growth stages $(p<0.05)$. 

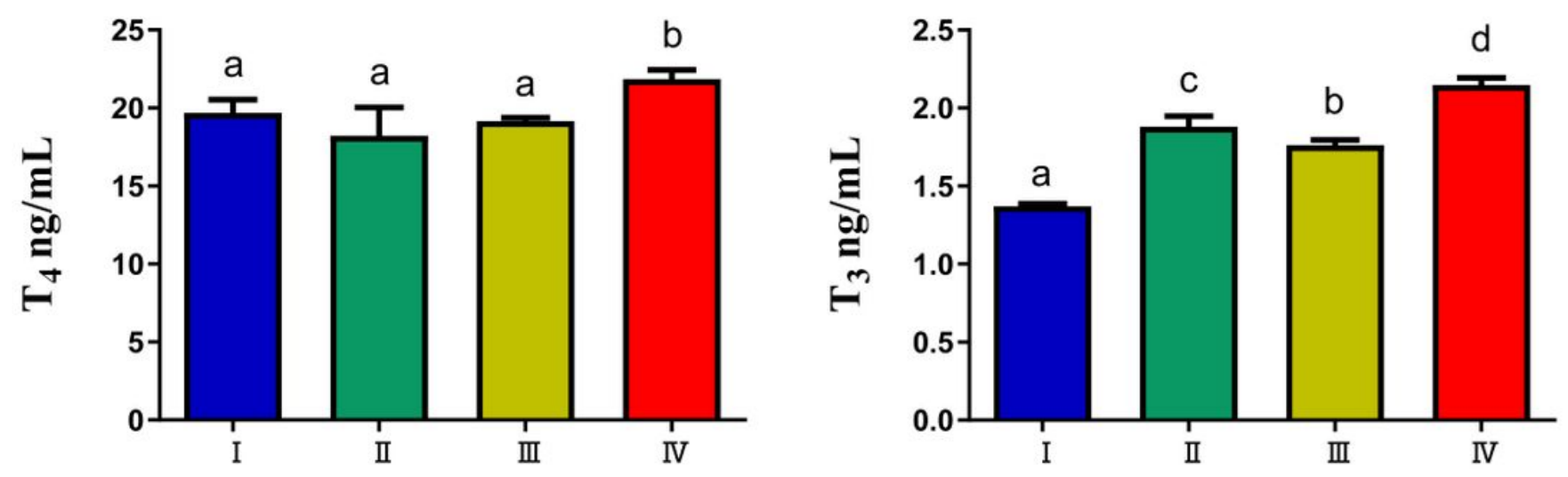

a growth stage

b growth stage

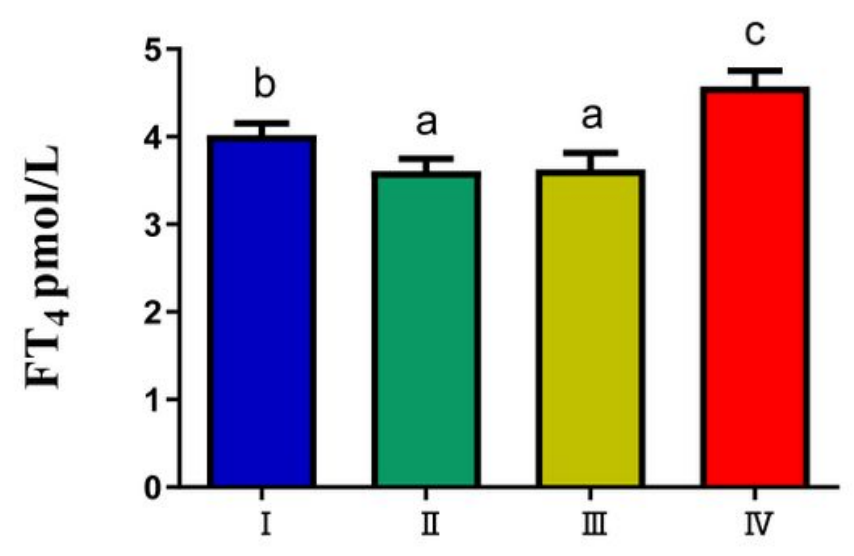

C growth stage

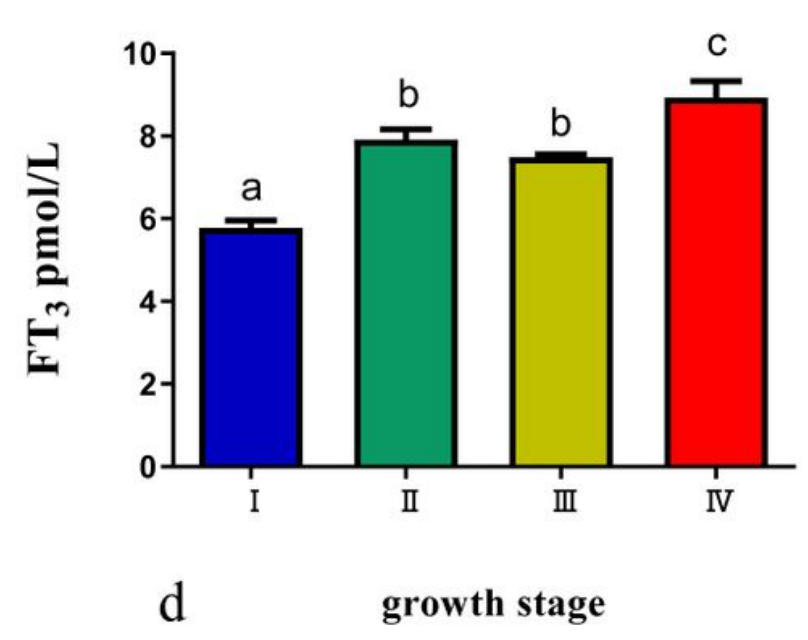

Figure 3

Changes of serum THs at different growth stages in 0. mykiss (a) Changes of serum T4; (b) Changes of serum T3; (c) Changes of serum FT4; (d) Changes of serum FT3. The THs in each growth stage is presented as mean $\pm S D(n=3)$. Different superscript letters indicate significant differences among different growth stages $(p<0.05)$. 

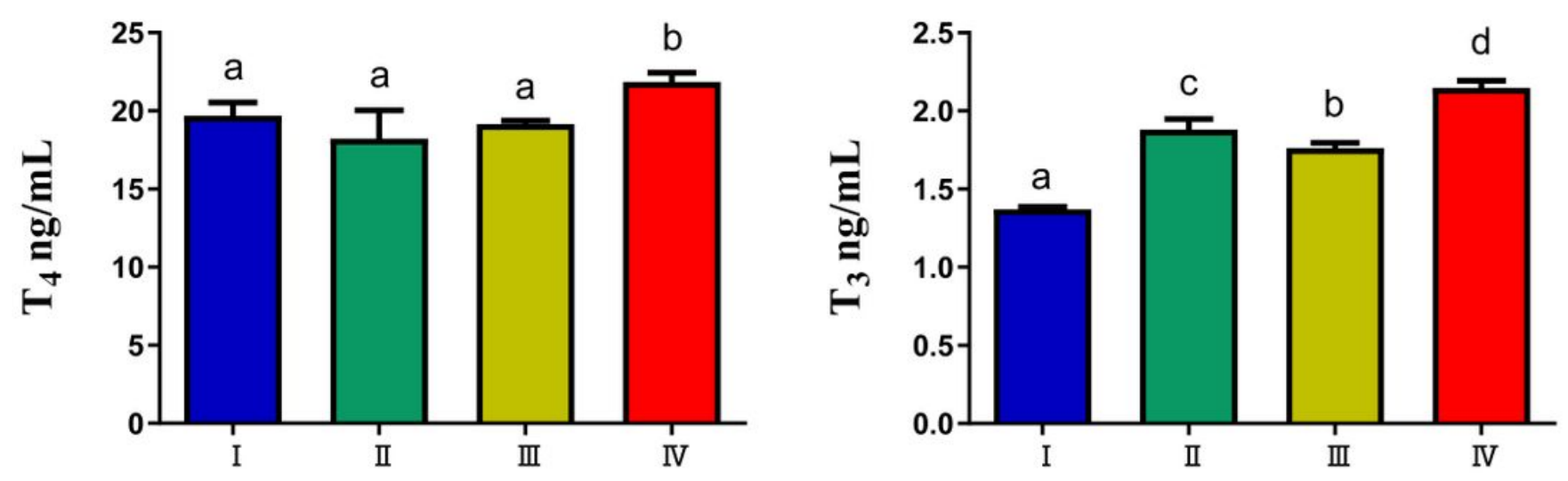

a growth stage

b growth stage

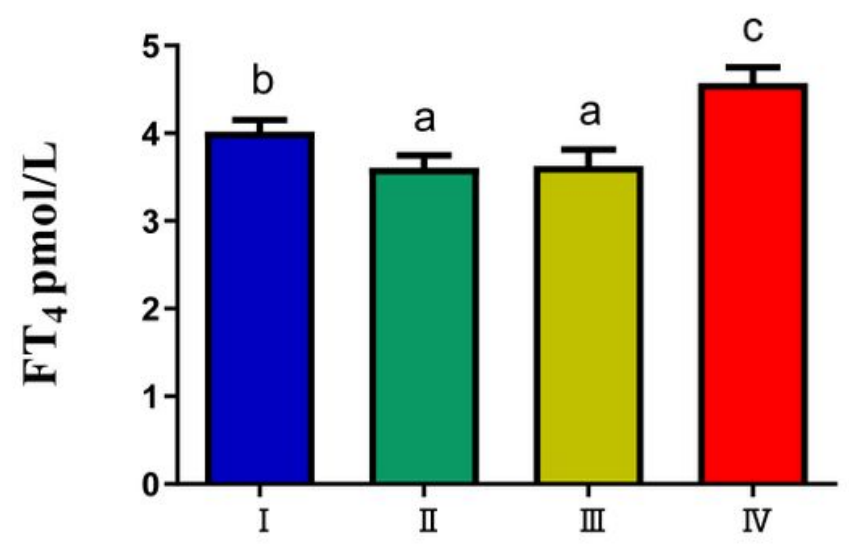

C growth stage

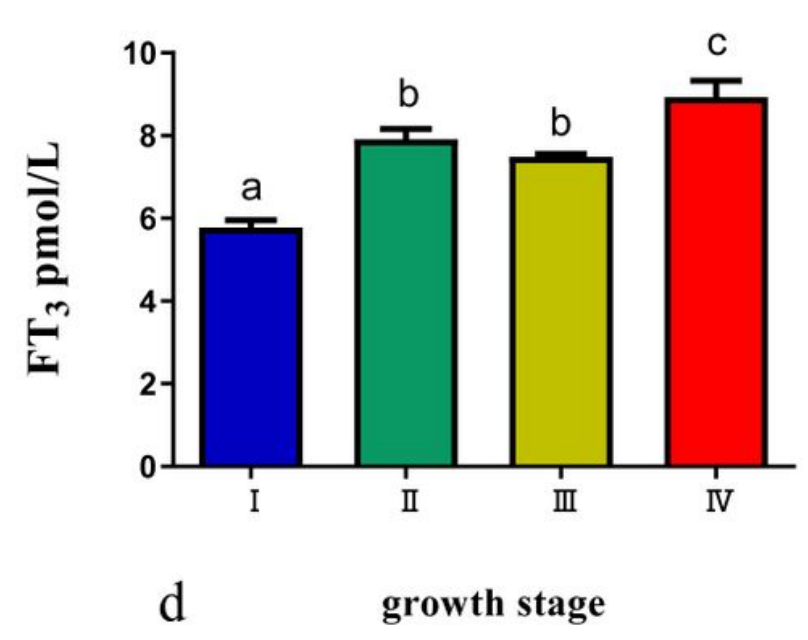

Figure 3

Changes of serum THs at different growth stages in 0. mykiss (a) Changes of serum T4; (b) Changes of serum T3; (c) Changes of serum FT4; (d) Changes of serum FT3. The THs in each growth stage is presented as mean $\pm S D(n=3)$. Different superscript letters indicate significant differences among different growth stages $(p<0.05)$. 


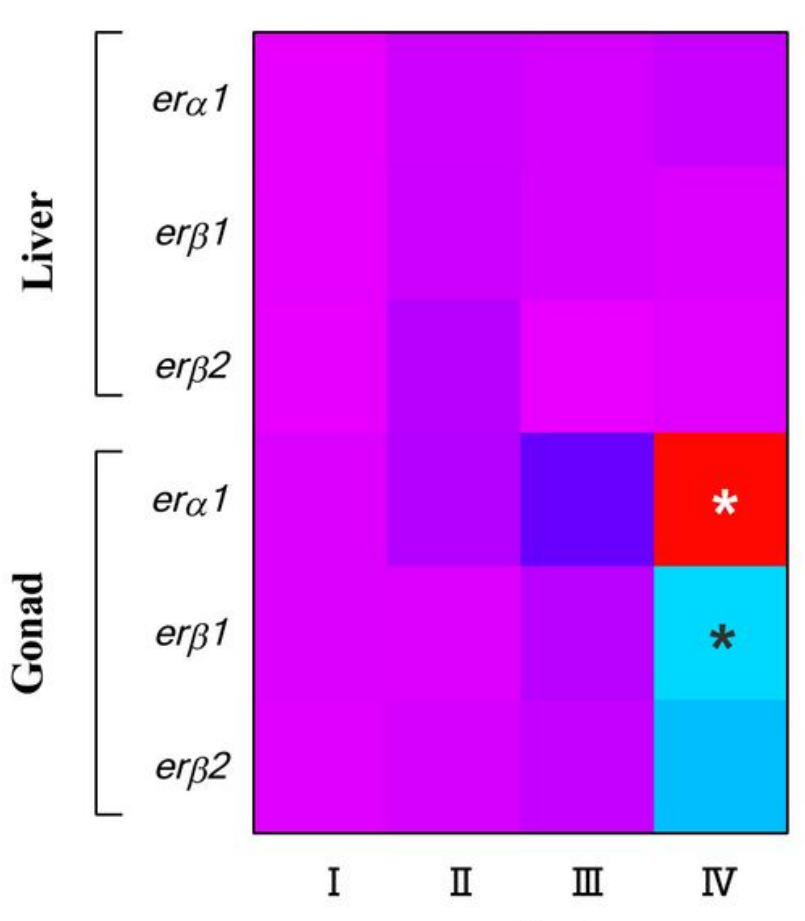

a

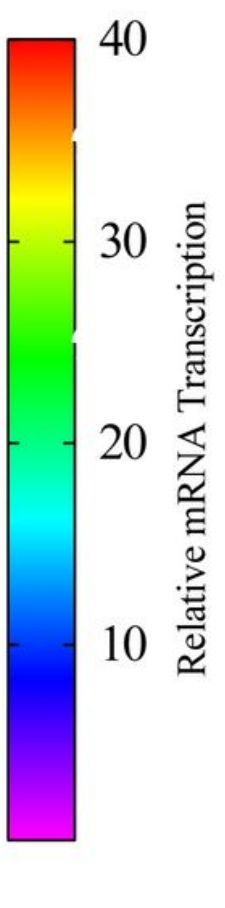

b
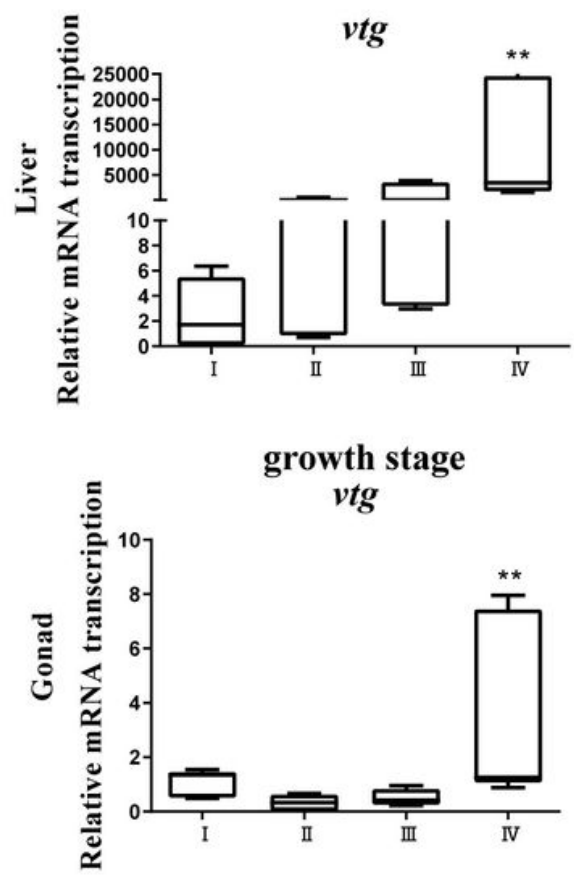

growth stage

\section{Figure 4}

Relative transcriptions of sex-related genes of O. mykiss at different growth stages (a) heatmap of ers mRNA transcription in liver and gonad, red represents a higher transcription and purple represent a lower transcription. (b) vtg transcription level in liver and gonad. Values significantly difference are indicated by asterisks $\left({ }^{\star} p<0.05,{ }^{* \star} p<0.01\right)$. 


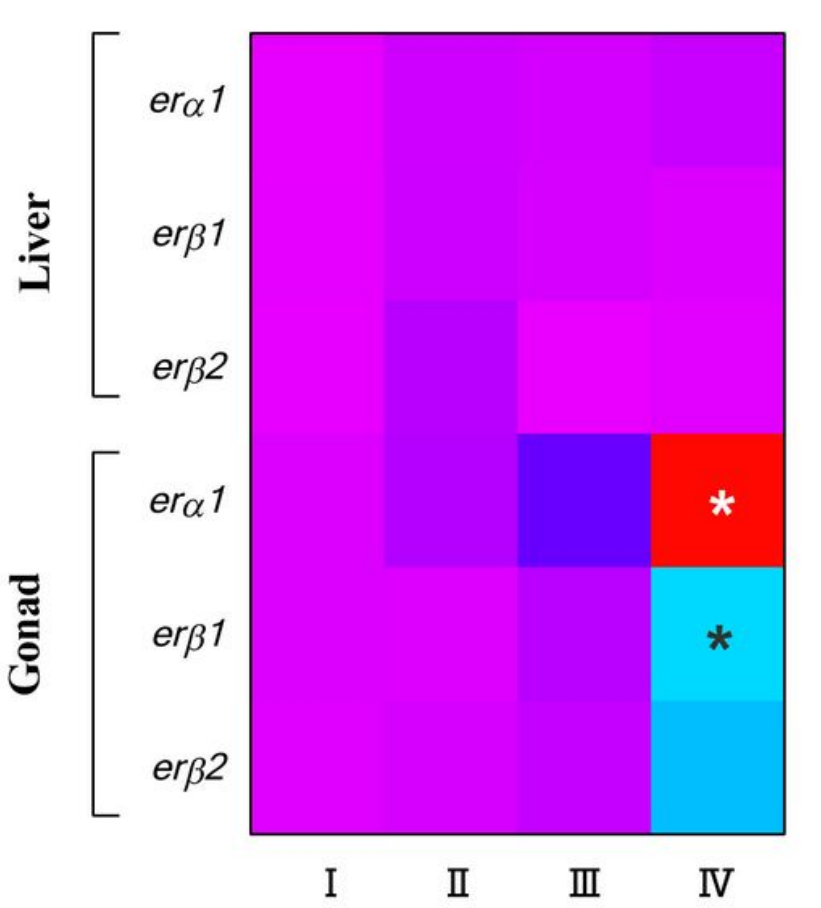

$\mathrm{a}$

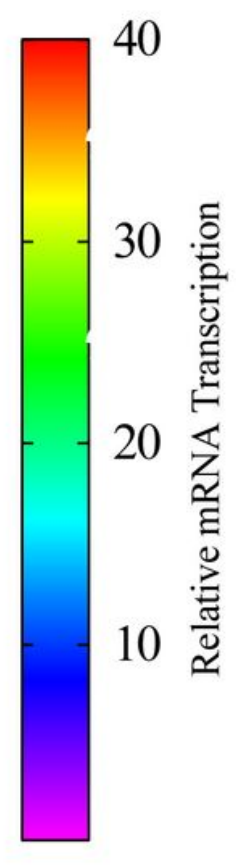

$\mathrm{b}$
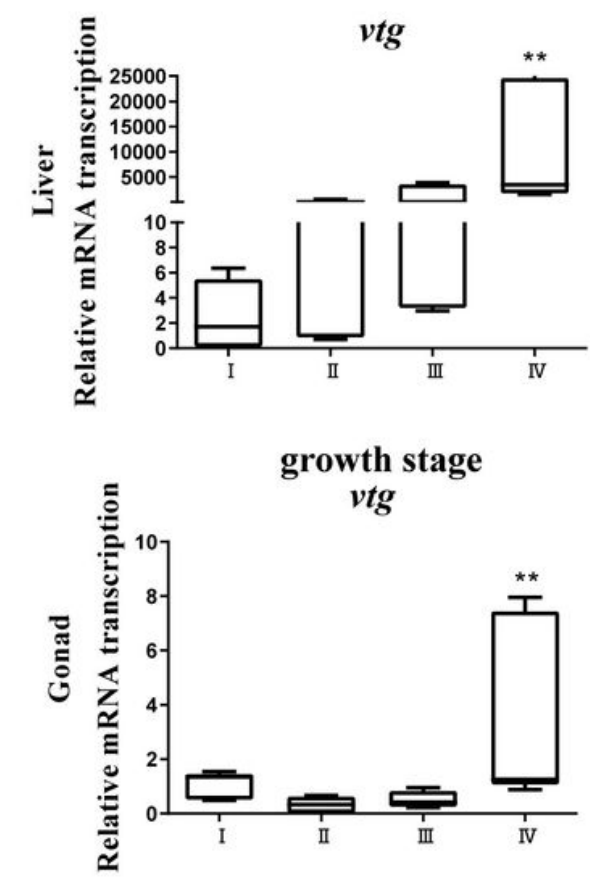

growth stage

Growing

\section{Figure 4}

Relative transcriptions of sex-related genes of O. mykiss at different growth stages (a) heatmap of ers mRNA transcription in liver and gonad, red represents a higher transcription and purple represent a lower transcription. (b) vtg transcription level in liver and gonad. Values significantly difference are indicated by asterisks $\left({ }^{\star} p<0.05,{ }^{\star *} p<0.01\right)$.

\section{Supplementary Files}

This is a list of supplementary files associated with this preprint. Click to download.

- ARRIVEchecklist.doc

- ARRIVEchecklist.doc 